European colonization, which acted particularly by disturbing the uninhabited no man's land (Grenzwildnisse) which separated tribal areas and kingdoms and which provided mechanisms for adjustment between different tribal groups and with their environment.

Ford marshals an impressive amount of information to support his thesis, delineating the development of affairs in all his five areas. The reader new to the field may find the diversity of the material bewildering, including, as it does, geology, palaeontology, historical fragments, excerpts from the diaries of early travellers, oral tradition, geographical description, entomology, and human and animal demography, all developed together with great profusion of detail so that any individual body of data is difficult to isolate, examine and assess. Nevertheless, the result is of great interest and, whether one agrees or not with Ford's thesis, the book will always be valuable, if only for the amount of data, otherwise difficult to obtain, amassed within it.

In his final chapter, Ford is apprehensive of epidemiological upsets at the termination of the colonial empires as profound as those which attended their establishment and cites present indications from the Congo and the Sudan. He emphasizes, again, the need to relate disease control to expected economic growth rate. He urges the development of the mathematical epidemiology of trypanosomiasis. He laments the neglect of entomologists to study, at the same time as the habits of their insects, also the habits of the people and the animals bitten. He hopes for a better balance under political freedom than has happened under colonial rule. This is questionable and indeed, under the more general approach to trypanosomiasis study in recent years, this lack has been realized and much done to repair it. To my mind, however, much of the uncertainty and misapprehension in the field of trypanosomiasis does indeed derive from the paucity of integrated studies. Trypanosomiasis contrasts sharply in this respect with some other tropical diseases, such as yellow fever, in which integrated teams fairly rapidly worked out the main essentials of the epidemiology, in both South America and Africa.

Considerable progress in integrated studies was indeed made by the East African Trypanosomiasis Research Organization and is indeed still continuing in spite of the dislocation caused by the loss of long-experienced personnel consequent on the granting of independence to East African territories in 1962-63.

The book is well illustrated with line diagrams and is fully indexed. There is a bibliography of some 600 sources.

W. H. R. LUMSDEN
Molecular Pharmacology Essentials of Molecular Pharmacology : Background for Drug Design. By Andrejus Korolkovas. Pp. xv+339. (Wiley Interscience: New York and London, November 1970.) 160s.

THE term molecular pharmacology is of recent currency but may be taken to indicate a new determination among pharmacologists to account for the nature and specificity of drug action in terms of a detailed description of events at the atomic level. Speculation at this level has of course been rife for years but hard facts have been few, and it is really the arrival of new techniques, notably X-ray crystallography of proteins, that have given a great new impetus to this challenging subject. This book deals with the major areas of activity so far including adequate accounts of intermolecular forces and the analysis of chirality. The account of drug-receptor interactions is imaginative and stimulating, but it is here that the weaknesses in contemporary pharmacological arguments become so clear - the argument is based on analogy with enzyme-substrate interactions (themselves not understood unequivocally), and extrapolations from structure activity studies.

The position is rapidly developing where drug binding directly to receptors is possible so that the analogies may be put aside, but as the $\mathrm{X}$-ray studies of binding of enantiomeric glycosides to lysozyme, and isomeric nucleotides to ribonuclease have shown, changes in structure of the ligand may entail a major change in the geometry of the complex that cannot be predicted from structure activity studies. The implication is that structural techniques, particularly X-ray crystallography and nuclear magnetic resonance, must be decisive tools for the molecular pharmacologist.

The theories of drug action discussed in this book are bound to become rapidly clarified as the study of isolated receptors proceeds. It is interesting to see how history repeats itself. The isolation and crystallization of enzymes was inhibited by vitalistic concepts, the isolation of receptors was similarly inhibited by beliefs that receptors could not survive isolation from their environment in membranes; lo and behold, when isolated they are as tough as old boots. Nevertheless, we must not be carried away by excessive optimism, isolation of receptors will not answer all the questions of drug action any more than isolation of enzymes solves the problem of how enzymes work, but it does have the enormous advantage of replacing mystery by tangibility.

For the rapid development of molecular pharmacology that is now just beginning, this book provides a useful and interesting primer that can be strongly recommended.

$$
\text { A. S. V. BURGEN }
$$

\section{Complex Chemistry}

Organometallic Chemistry. Edited by F. G. A. Stone and M. I. Bruce. (Plenary Lectures at the Fourth International Conference on Organometallic Chemistry, held at Bristol, UK, July 28August 1, 1969.) (International Union of Pure and Applied Chemistry in conjunction with the Chemical Society, London. Pure and Applied Chemistry, Vol. 23, No. 4, 1970.) Pp. 375-503. (Butterworth: London, 1970.) £3.50.

Publication, in a hard-cover version, of the proceedings of symposia of the Internation Union of Pure and Applied Chemistry has complemented, for the past few years, their normal appearance in the journal Pure and Applied Chemistry. One would not have guessed that such a double-barrelled approach would have been profitable for the publishers-it must be a tribute to the balance and high quality of reviews which appear in this volume and in its predecessors.

So far, the only characterized organometallic complex occurring in nature is vitamin $\mathbf{B}_{12}$, and its chemistry is better understood now through the systematic studies of metal complexes of porphins, corrins and corroles. These are reviewed by A. W. Johnson. K. Schlögl concentrates his attention on chirality in the metallocenes and the summary serves as a general reminder that the optical activities of organometallic catalysts and stereospecificity of polymerization reactions could be a renewed focus of interest in the near future. Gubin surveys the information which electrochemical methods have given on energy levels and bonding in the metallocenes and cyclopentadienyl metal carbonyls and Chini completes our exposure to transition metal chemistry by a succinct summary of the chemistry of a number of carbonyl clusters of the iron and cobalt triads.

It is good to see main group organometallic chemistry so well represented. Brown gives a particularly nice account of nuclear magnetic resonance studies of structure and exchange reactions of organolithium compounds; Seyferth summarizes insertion reactions of methylene bridges into group IV hydrides and halides while Neumann emphasizes the free radical chemistry of organotin compounds.

Obviously, individual volumes can have no claim to comprehensiveness but together they represent a most valuable addition to the secondary literature.

R. MASON 